\title{
GRUPO DE ESTUDOS AFRO-BRASILEIROS (GEAB): REFLEXÕES SOBRE A EDUCAÇÃO DAS RELAÇÕES ÉTNICO- RACIAIS
}

\section{AFRO-BRAZILIAN STUDIES GROUP (GEAB): REFLECTIONS ON THE EDUCATION OF ETHNIC-RACIAL RELATIONS}

\author{
Daniel Péricles Arruda \\ Universidade Federal de São Paulo - UNIFESP
}

\section{RESUMO}

Neste artigo, são apresentadas reflexões a partir de experiências no Grupo de Estudos Afro-brasileiros (Geab), vinculado ao Núcleo de Inclusão Racial (NIR), da Pontifícia Universidade Católica de Minas Gerais (PUC Minas). Esse grupo consistia-se como referência no estudo e na produção de conhecimento científico acerca da realidade racial; em auxiliar a universidade acerca dessa temática. Dessa maneira, o estudo apoia-se na abordagem qualitativa documental e na base teórica interdisciplinar. Ao analisar as experiências do Geab, conclui-se que esse grupo corroborou significativamente no debate acerca das relações étnico-raciais, em especial, sobre o racismo e as cotas raciais - temas efervescentes naquele contexto -, e possibilitou que vários/as discentes pudessem se reconhecer e se afirmar negros/as e tivessem o entendimento, a fundamentação teórica e o posicionamento crítico acerca dessas questões.

Palavras-chave: Educação; Ensino Superior; Geab; Relações Étnico-raciais; PUC-MG.

\begin{abstract}
This article includes reflections from experiences in the Group of Afro-Brazilian Studies (Geab), linked to the Nucleus of Racial Inclusion (NIR) of the Pontifical Catholic University of Minas Gerais (PUC Minas). The group is a reference in the study and the production of scientific knowledge on the racial reality to aid the university in this subject. Thus, the study uses the qualitative documentary approach and is interdisciplinary and theoretical based. Analysis of the experiences of Geab concluded that this group corroborated significantly to the debate about ethnic-racial relations, especially on racism and racial quotas - effervescent themes in that context - and allowed several students to recognize and affirm their black identity plus obtain the understanding, theoretical foundation, and critical position on these issues.
\end{abstract}

Keywords: Education; Higher education; Geab; Ethnic-Racial Relations; PUC-MG. 


\section{INTRODUÇÃO}

O final da década de 1990 e os primeiros anos da década de 2000 foram marcados por acontecimentos relevantes, no que diz respeito ao tema das relações étnico-raciais, principalmente no que se refere à violência de Estado contra a população negra; ao preconceito e à discriminação étnico-racial; às ações afirmativas - em que se destacava o debate sobre as cotas raciais nas universidades ${ }^{1}$-; e o debate político sobre a questão racial em âmbito mundial, em especial, na III Conferência Mundial contra o Racismo, a Discriminação Racial, a Xenofobia e Intolerância Correlata, ocorrida entre agosto e setembro de 2001, em Durban/África do Sul². Até 2001, de acordo com Munanga (2015), esse debate não tinha lugar na grande mídia, no âmbito governamental, por exemplo, exceto entre alguns/algumas estudiosos/as e pesquisadores/as que se aplicavam à questão nos espaços acadêmicos e/ou intelectuais.

Toma-se essa conferência como principal evento daquele contexto, para compreender sua construção e seu objetivo articulados à realidade brasileira. Considera-se que Durban não foi a cidade anfitriã por acaso, ou seja, de acordo com Ziegler (2011, p. 71):

Durban foi escolhida porque é uma cidade de médio porte, consequentemente, capaz de facilitar os contatos humanos fora das salas de conferência. Além disso, está situada às margens do oceano Índico, ao pé das montanhas de KwaZulu. Seu clima é ameno, sua população é cosmopolita - uma mistura de indianos, tamouls, chineses, africânderes, xosa, zulus, makondés (do Moçambique) etc.

O debate acerca das relações étnico-raciais, promovido em Durban, envolveu tensões, conflitos, a explanação de variadas concepções históricas; por isso que o encontro de lideranças de diversos países para traçar caminhos e ações efetivas para enfrentar o racismo, certamente, teve, inicialmente, que se pautar por uma finalidade apresentada, na conferência, pelo secretário-geral das Nações Unidas, Kofi Annan (apud ZIEGLER, 2011, p. 71-72):

\footnotetext{
${ }^{1}$ Vide Lei Federal 12.711/2012 (Lei de Cotas) que versa sobre o ingresso nas universidades federais e nas instituições federais de ensino técnico de nível médio e dispõe sobre outras providências.

2 É importante dizer que as Conferências Mundiais contra o racismo são eventos internacionais realizados em 1978, 1983, 2001, 2009 e a última, até o momento, em 2018: V Conferência sobre Combate às Desigualdades Econômicas, Raciais e Étnicas, na cidade de Vitória/ES.
} 
Que objetivo tinha essa conferência? Em seu discurso de abertura, Kofi Annan respondeu a essa pergunta: "Por intermédio de seus descendentes, os mortos pedem que justiça seja feita [...]. A dor e a cólera perduram. A comunidade internacional deve responder aos anseios do mundo inteiro". Tratava-se, ele explicou ainda, de banir a violência nascida dos "demônios identitários".

A conferência de Durban foi um evento marcado por vários interesses em disputa e por narrativas contundentes voltadas ao desejo de reparação histórica. É o que demostra o discurso do presidente do Senegal, Abdoulaye Wade (apud ZIEGLER, 2011, p. 77):

\begin{abstract}
O que queremos é que a humanidade compreenda que, em dado momento de sua evolução, um dano incalculável nos foi causado, uma grande injustiça foi praticada contra nós. O que nos queremos é que as gerações atuais e futuras compreendam isso. Para tanto, penso que os países desenvolvidos e, de forma mais genérica, a comunidade internacional deveriam fazer com que a escravatura e o tráfico negreiro constem do programa escolar das crianças, dos cursos universitários, dos programas de pesquisa. Estelas e monumentos deveriam ser erigidos e filmes feitos para apresentar essa história em toda a sua autenticidade. Os arquivos, e digo todos os arquivos, deveriam poder ser consultados por pesquisadores de todos os países do mundo.
\end{abstract}

Em Durban ficou evidente que além do racismo ter deixado marcas de sofrimento e desamparo na história e na memória de vários povos, deixou também feridas que não cicatrizaram, ou seja, consequências causadas pela escravização e pelo racismo. A conferência deflagrou intenso debate público, envolvendo tanto órgãos governamentais quanto não governamentais, interessados na elaboração de propostas com vistas ao enfrentamento do racismo, mas a conferência - por reunir vários países que, historicamente, foram colonizadores e outros colonizados por esses - foi o cenário de acusações, reinvindicações e luta por reparações históricas. Ziegler (2011, p.76), afirma que "Em Durban, insultos e críticas brotaram de ambos os lados, de manhã à noite. Delegados deixavam a sala de conferência batendo a porta, voltavam, vociferavam, retiravam-se de novo".

No caso brasileiro, durante o contexto das discussões internacionais sobre o racismo e dos reflexos dessa conferência, considera-se as lutas e reivindicações históricas do Movimento Negro e, na mesma década em que ocorreu o evento, aqui no 
Brasil a elaboração e a aprovação das leis 10.639/2003 3 e 11.645/20084, que inseremse no cerne das propostas de Durban. Por isso, sobre esse aspecto, Munanga (2015, p. 23) considera que "As polêmicas e controvérsias a respeito dessas políticas são indicadores das realidades de uma sociedade que ainda vive entre o mito e os fatos, ou melhor, que confunde o mito e os fatos, ou seja, onde o mito funciona como verdadeira realidade". O autor refere-se ao mito da democracia racial, que nega a existência do racismo, que oculta os conflitos e as violências contra negros/as e indígenas, expressando um convívio sem preconceitos e discriminações. E os fatos, tratam-se da materialidade, dos fatos reais, de reconhecer a história que foi distorcida e rejeitada. Esses são tópicos essenciais para se pensar e agir criticamente sobre a educação das relações étnico-raciais, inclusive, a importância da memória nesse processo:

A memória da escravidão no Brasil é ora esquecida ou negada, ora descrita negativamente como uma simples mercadoria ou uma força animal de trabalho sem habilidades cognitivas. A construção da memória da escravidão começa por justificativas ideológicas. Estas apresentam a escravidão como um gesto civilizador para integrar o africano na "civilização humana" (MUNANGA, 2015, p. 29).

Esse contexto também intimou as universidades brasileiras, públicas e privadas, a promoverem debates sobre as Políticas de Ação Afirmativa e cotas raciais, além de outros temas ligados às relações étnico-raciais no país, que vieram à tona naquele momento. Sobre esse debate temos importantes contribuições. A saber, de GOMES (2001b, p. 132) que diz:

As ações afirmativas se definem como políticas públicas (e privadas) voltadas à concretização do princípio constitucional da igualdade material e à neutralização dos efeitos da discriminação racial, de gênero, de idade, de origem nacional e de compleição física. Na sua compreensão, a igualdade deixa de ser simplesmente um princípio jurídico a ser respeitado por todos, e passa a ser um objetivo constitucional a ser alcançado pelo Estado e pela sociedade.

\footnotetext{
3 “Altera a Lei no 9.394, de 20 de dezembro de 1996, que estabelece as diretrizes e bases da educação nacional, para incluir no currículo oficial da Rede de Ensino a obrigatoriedade da temática "História e Cultura Afro-Brasileira", e dá outras providências".

4 “Altera a Lei no 9.394, de 20 de dezembro de 1996, modificada pela Lei no 10.639, de 9 de janeiro de 2003, que estabelece as diretrizes e bases da educação nacional, para incluir no currículo oficial da rede de ensino a obrigatoriedade da temática "História e Cultura Afro-Brasileira e Indígena".
} 
Já Gomes (2003, p. 77), pondera que:

As políticas de ação afirmativa significam uma mudança de postura, de concepção e de estratégia do Estado, da Universidade, do mercado de trabalho, os quais, em nome do discurso da igualdade, aplicam políticas e estabelecem critérios de seleção, ignorando a ressonância, nesses processos, de fatores como sexo, raça e cor.

Como outras instituições, a PUC Minas cedeu espaço para a realização de seminários relacionados à temática. Os eventos foram organizados por alguns/algumas professores/as da própria instituição, que, diante daquele cenário, se reuniram para formar o Núcleo de Inclusão Racial da PUC Minas (NIR).

De início, um dos objetivos do NIR foi inserir a comunidade acadêmica da PUC Minas no debate acerca das políticas de ações afirmativas e cotas raciais que se alastrava país afora.

Vinculado à Pró-reitoria de Extensão (Proex), por meio da Sociedade Inclusiva, o NIR implementou ações, como o Grupo de Estudos Afro-brasileiros (Geab); o programa Afrocidadania; os Projetos Afroeducação; Afrocine; Afroconsciência; os eventos: Semana da Consciência Negra; e Circuito PUC Minas de Arte e Cultura Negra; além de parcerias, como o Curso de Pós-graduação em Estudos Africanos e Afrobrasileiros; o Seminário Internacional Brasil-África; e o projeto Cultura Afro nas Escolas.

O Geab - objeto de análise deste estudo, existiu na PUC Minas de 2003 a 2009 - e consistia-se como referência no estudo e na produção de conhecimento científico acerca da realidade racial, na referência em auxiliar a universidade acerca dessa temática, e, por ter sido um grupo voltado para a pesquisa e as ações/intervenções educativas e culturais; também servia de apoio e referência militante para discentes negros/as e/ou interessados em discutir as relações étnico-raciais. Era um grupo interdisciplinar constituído por discentes da PUC e de outras instituições de várias áreas do conhecimento, bem como aberto à comunidade.

A educação das relações étnico-raciais é defendida em estudos de Silva e Tobias (2016), que ao desenvolverem uma intensa revisão bibliográfica, constataram que a discriminação racial, entre os/as autores/as analisados, é o aspecto relevante para a continuidade das desigualdades raciais, articuladas aos anseios de políticas de ação afirmativa. Em Miranda (2017), identificamos os desafios da política de identidade no âmbito do debate racial na universidade no Brasil. Em Gomes (2018), que faz expressiva reflexão sobre a luta contra o racismo na sociedade brasileira que o camufla 
por meio das enunciações da democracia racial, porém o revela em tempo de tensões e acirramentos ideológicos e políticos.

Portanto, é na esteira dessa luta que considera-se adequado resgatar e transmitir a atuação desse grupo para identificar e refletir sobre as suas contribuições para o campo da educação, com foco na implementação de políticas públicas, que considerem a importância do reconhecimento do estudo sobre a diversidade étnicoracial e da condição de discentes negros/as no universo acadêmico.

\section{Procedimentos metodológicos}

O estudo partiu de uma indagação norteadora: Quais foram as contribuições do Geab em prol da educação das relações étnico-raciais?

Nessa perspectiva, a construção do caminho metodológico baseou-se na pesquisa qualitativa, com base nos documentos do Geab, como anotações de encontros, diários, imagens, flyers das atividades. Considera-se qualitativa pois “[...] parte do fundamento de que há uma relação dinâmica entre o mundo real e o sujeito, uma interdependência viva entre o sujeito e o objeto, um vínculo indissociável entre o mundo objetivo e a subjetividade do sujeito" (CHIZZOTTI, 2010, p. 79).

Isto é, a pesquisa considerou também os aspectos culturais, políticos e subjetivos emergentes das relações étnico-raciais, bem como o contexto social do debate, seja no Brasil ou na esfera internacional.

Os documentos referem-se a "toda informação sistemática, comunicada de forma oral, escrita, visual ou gestual, fixada em um suporte material, como fonte durável de comunicação" (CHIZZOTTI, 2010, p. 109).

Nessa ótica, por meio da pesquisa documental, foi possível apreender o contexto e desenvolvimento do Geab a partir da análise de diário de campo, fotografias, planilhas de controle, fichamentos, anotações de eventos culturais e atividades acadêmicas. Esses elementos foram essenciais para a apreensão dos resultados, bem como de sua exposição de modo reflexivo.

\section{A juventude negra no ensino superior}

No final dos anos 1990, o grupo de rap Racionais MC's lançou um álbum intitulado "Sobrevivendo no Inferno"; considerado um dos mais importantes da 
cultura hip-hop, visto que praticamente todas as músicas tiveram destaque, em especial, a música Capítulo 4, Versículo 3, que, na introdução, na voz de Primo Preto, anuncia:

$60 \%$ dos jovens de periferia sem antecedentes criminais já sofreram violência policial/ A cada quatro pessoas mortas pela polícia, três são negras/ Nas universidades brasileiras apenas $2 \%$ dos alunos são negros/ A cada quatro horas, um jovem negro morre violentamente em São Paulo/ Aqui quem fala é Primo Preto, mais um sobrevivente (RACIONAIS MC's, 2018, p. 49).

Os dados apresentados por Primo Preto reafirma a condição da juventude negra na passagem do século XX para o XXI. Naquela conjuntura, essa música reacendeu o debate sobre as relações étnico-raciais no País. A música virou hino, para a juventude periférica. Ecoou por vários espaços sociais, alcançando, inclusive, a juventude de outras raças/cores e classes sociais.

A música veio em um momento oportuno; agregou força aos movimentos de combate ao racismo, e contribuiu na luta contra a invisibilidade da questão racial. E fomentou ações contra essa fatídica realidade.

Porém, na atualidade, de acordo com Almeida (2019), percebe-se que as engrenagens do racismo estrutural ainda corroboram para que a população negra do Brasil ocupe posições socialmente inferiores e que, dentre as suas diversas ideologias, há o movimento em prol de legitimar, cada vez mais, a ideia de que "somos todos iguais"; que a cor da pele não influencia nas relações sociorraciais.

Assim, a lógica do mérito acaba por ser outro artifício de transferir um problema historicamente racial, e coletivo, para o indivíduo isolado, em razão de suas qualificações profissionais, habilidades e competências. Isto é, nesse frágil e perigoso raciocínio, não se consideram os contextos das relações sobre raça/cor e nem outros aspectos da vida, e sim o sucesso particular, como resultado de alguma conquista que se deu pela via do esforço de cada um/a. O mérito é, portanto, uma forma de desviar das raízes da questão e impor uma ordem de ranqueamento por meio da premiação daquele/a que chega primeiro.

Esses aspectos afloraram em muitos debates realizados no Geab, pois, como havia menos negros/as nas universidades e mais negros vitimados pela violência letal do Estado, era notório que algo precisava ser feito. Inclusive, no espaço acadêmico, o qual deve (ou deveria) estar voltado para os problemas sociais; aberto para a comunidade; e em promover ações educativas com diversos setores da sociedade. 
Inclusive, conforme Munanga e Gomes (2006, p. 178) “[...] refletir sobre a questão do negro não é algo particular que só deve interessar às pessoas que pertencem a esse grupo étnico-racial ou aos militantes do Movimento Negro. É uma questão da sociedade brasileira e também da humanidade".

No Geab, foi possível perceber que aumentar o número de negros/as não era apenas uma questão quantitativa, mas também de equiparação, representatividade e direitos. Percebia-se também que a admissão de um/a discente negro/a era um passo importante, e que eram necessárias condições para que esse/a aluno/a permanecesse na instituição em condições satisfatórias para o seu desenvolvimento acadêmico e que pudesse continuar sua trajetória universitária, caso desejasse; que soubesse que aquele espaço era um local de referência acerca das relações étnico-raciais e que seria relevante a sua disposição em posicionar-se coletivamente. O diálogo, o trato com as palavras, a fundamentação das ideias e saber compreender e relacionar-se politicamente são, portanto, aspectos fundamentais e parte das relações étnico-raciais.

Entretanto, o fato de um/a discente negro/a estar em uma universidade, não significa inclusão racial propriamente dita, ou seja, pode ocorrer a inclusão enquanto número, mas não enquanto reconhecimento e pertencimento deste, na perspectiva de ações para sua manutenção, de sua relação particular com as desigualdades raciais e sociais as quais são históricas e estruturantes no Brasil, pois de acordo com Senkevics (2018, p. 2), "A educação superior brasileira é palco de persistentes desigualdades raciais que comprometem, até os dias de hoje, a garantia do direito pleno à educação para a população". Sendo questão de direito, o Estado, conforme Senkevics (2018), não dispõe de condições satisfatórias para desenvolver precisamente a avalição e o monitoramento da política. Assim, sem o acompanhamento da execução de uma ação inclusiva, corre-se o desvirtuar os objetivos em pauta, precarizar a oferta e responsabilizar o/a estudante por um possível equívoco devido à ausência de uma realidade não reconhecida nos dados e nem no cotidiano acadêmico sobre a juventude negra.

\section{A organização do Grupo de Estudos Afro-Brasileiros (Geab)}

O Geab foi implementado primeiramente na PUC Minas Coração Eucarístico; depois, na PUC Minas São Gabriel e PUC Minas em Contagem, tendo por referência, na organização, a Profa. Dra. Iris Amâncio, que foi coordenadora do NIR de fevereiro

@rquivo Brasileiro de Educação, Belo Horizonte, v. 9, n. 18, 2021 
de 2002 a outubro de 2009. Na época, a intenção era que os demais campus da PUC Minas também tivessem o Geab, como as unidades Barreiro, Betim, Arcos e Serro.

Questão primordial do Geab, foi a sua institucionalização formal dentro da PUC (implicava o recebimento de recursos financeiros da instituição para o custeamento de atividades); a sistematização dos encontros contínuos e dos temas a serem discutidos; a elaboração de calendário sobre as atividades a serem desenvolvidas durante o semestre; e a articulação com outras instituições e a comunidade.

A organização do Geab deu status e credibilidade ao grupo, possibilitando a participação de professores/as da universidade na condução dos encontros e, quando possível, o repasse de recursos financeiros para o desenvolvimento de ações, considerando as especificidades de cada campus. Esses aspectos falam da diversidade racial e cultural do grupo que construía projetos criativos e plurais, sem desconsiderar currículos e sistemas de avaliações (IVENICKI, 2018).

\section{Ancestralidades e processos de construção de identidades}

Para os componentes do Geab, discutir a realidade racial do/a negro/a no Brasil, exigia conhecer a história da África. Por isso, o processo de construção desse grupo contou com a desconstrução histórica do que, comumente, muitos, aprenderam, de modo equivocado/alterado, antes de entrar na universidade. Certamente, de acordo com Munanga e Gomes (2006, p.32), "Muito do que conhecemos da África chega até nós pelos meios de comunicação de massa. Filmes como os de Tarzan e outros popularizados no cinema e na TV trazem para nós imagens distorcidas do povo africano, de suas tradições e sabedoria”.

Como o Brasil tem a segunda maior população negra fora da África, é fato que parte significativa desses sujeitos negros e negras não conhece suas origens étnicas. Por isso, é preciso refletir os processos educativos, raciais e culturais do Brasil que, historicamente, não se preocuparam em construir uma sociedade voltada para o reconhecimento e respeito às diversidades culturais, voltadas para práticas antirracistas e que visem reparações históricas.

Nessa reflexão, ocultar a história de um povo, ensinar narrativas equivocadas, obstruir o desenvolvimento da memória, são algumas formas de alterar a formação de sua identidade, ou seja: 
A memória faz variar o ponto de vista, distende conceitos duros, solta o corpo ajustado, faz viver os mortos. A memória inspira, recupera a graça do tempo, devolve o entusiasmo pelo que era caro e se perdeu, redime o sagrado. A memória devolve não simplesmente o passado, mas o que o passado prometia. A memória devolve o que o passado vislumbrou e o presente esqueceu (FILHO In: BOSI, 2003, orelha da obra).

Assim, contra o esquecimento/apagamento da África, estudá-la possibilitou aos integrantes do grupo desenvolverem críticas em relação a muitas histórias que apresentavam apenas o lado negativo daquele continente. No grupo, tornou-se pertinente retomar a construção da imagem do povo africano, até mesmo por considerar a África como berço de diversas civilizações (MUNANGA e GOMES, 2006), para então compreender os processos de escravização no Brasil e as relações étnicoraciais do tempo presente.

Essa questão foi discutida pelo Prof. Dr. Kabengele Munanga em palestra proferida na III Semana Consciência Negra, na PUC Minas, em Contagem/MG, realizada no segundo semestre de 2004. Naquela ocasião, Munanga fez reflexões sobre a ancestralidade africana considerando que a história de um povo depende da preservação de sua cultura, sua memória e que a falta de conhecimento histórico deixa lacunas na compreensão da realidade. Munanga considerou também que as cotas raciais abrem caminhos para o enfrentamento das desigualdades raciais e do racismo.

Essas reflexões foram importantes para impulsionar a implementação do Geab naquele campus, contribuindo também para a reflexão sobre quem é o negro no Brasil, aspecto que Munanga (2004, p. 52) assim considera:

Parece simples definir quem é negro no Brasil. Mas, num país que desenvolveu o desejo de branqueamento, não é fácil apresentar uma definição de quem é negro ou não. Há pessoas negras que introjetaram o ideal de branqueamento e não se consideram como negras. Assim, a questão da identidade do negro é um processo doloroso. Os conceitos de negro e de branco têm um fundamento etno-semântico, político e ideológico, mas não um conteúdo biológico.

É complexa a formação identitária do/a negro/a brasileiro/a. É não é tão simples vivenciar o contexto acadêmico sendo negro/a. Por isso, ações coletivas voltadas para a troca de experiências e ações educativas são pertinentes para evitar equívocos históricos e práticas que possam produzir mais racismos. Por isso que, em vários encontros do Geab, foi importante o debate sobre o conceito de negro/a e como esse conceito opera, em corpos negros, na prática. 
Refletir sobre as cotas raciais como uma das estratégias das ações afirmativas se fez necessário, inclusive, a partir das contribuições de Joaquim Benedito Barbosa Gomes (2001a e 2001b). Sobre a iniciativa, Gomes (2001b, p. 135) expõe:

\begin{abstract}
As ações afirmativas podem ser definidas como um conjunto de políticas públicas e privadas de caráter compulsório, facultativo ou voluntário, concebidas com vistas ao combate à discriminação racial, de gênero, por deficiência física e de origem nacional, bem como para corrigir ou mitigar os efeitos presentes da discriminação praticada no passado, tendo por objetivo a concretização do ideal de efetiva igualdade de acesso a bens fundamentais como a educação e o emprego. Diferentemente das políticas governamentais antidiscriminatórias baseadas em leis de conteúdo meramente proibitivo, que se singularizam por oferecerem às respectivas vítimas tão somente instrumentos jurídicos de caráter reparatório e de intervenção ex post facto, as ações afirmativas têm natureza multifacetária (RESKIN, 1997) e visam a evitar que a discriminação se verifique nas formas usualmente conhecidas isto é, formalmente, por meio de normas de aplicação geral ou específica, ou por meio de mecanismos informais, difusos, estruturais, enraizados nas práticas culturais e no imaginário coletivo. Em síntese, trata-se de políticas e de mecanismos de inclusão concebidos por entidades públicas, privadas e por órgãos dotados de competência jurisdicional, com vistas à concretização de um objetivo constitucional universalmente reconhecido - o da efetiva igualdade de oportunidades a que todos os seres humanos têm direito (Itálicos do original).
\end{abstract}

Como a ação afirmativa implica uma reparação, no caso racial brasileiro, portanto, retomam-se as contribuições de autores como Biko (1978/1990), Munanga (2009), Memmi (1957/2007), Pétré-Grenouilleau (2009), que apresentam importantes contribuições que explicam os sentidos e significados dos processos da escravização, da colonização, da negritude e da consciência negra.

Consequentemente, ao modo de produção via escravização, já no modo de produção capitalista, faz-se necessário compreender a questão do/a negro/a na sociedade burguesa, ou seja, entender a relação entre questão racial e classe social, como se vê em Guimarães (2012) e Ianni (2004).

Em suma, o Geab foi um espaço de estudo e produção acadêmica e cultural. Fez parte do processo de discussão das políticas de ação afirmativa nas universidades brasileiras, questão pesquisada de modo aprofundado por Marçal (2012). Proporcionou diversas atividades contínuas, ao longo dos semestres, e não somente em uma data específica, mas como prática cotidiana nos campus da PUC Minas. Isto é, manteve vivas as posturas críticas e as vozes contra o racismo (RIBEIRO, 2019).

A luta dos/as discentes e professores/as envolvidos nesse processo, desse modo, foi pelo direito de serem reconhecidos em suas especificidades étnico-raciais e que a universidade assumisse o seu papel em discutir e promover ações consistentes acerca

@rquivo Brasileiro de Educação, Belo Horizonte, v. 9, n. 18, 2021 
dessa questão. Desse modo, o texto poético muito citado e referenciado durante as atividades do Geab, do Prof. Jorge Enrique Mendonza Posada, ilustra a concepção desse grupo, "Um Negro":

\author{
Um negro sempre será um negro, \\ Chama-se pardo, crioulo, preto, cafuso, \\ mulato ou moreno-claro \\ Um negro sempre será um negro: \\ na luta que assume pelo direito do emprego \\ e contra a discriminação no trabalho \\ Um negro sempre será um negro: \\ afirmando-se como ser humano \\ na luta pela vida \\ (POSADA, 1993, p. 13).
}

\title{
CONCLUSÃO
}

O Geab corroborou significativamente o debate acerca das relações étnicoraciais, em especial, sobre o racismo, as cotas raciais na universidade e a condição do/a docente e do/a discente negro/a no ensino superior.

Ao se preocupar com a pesquisa e o estudo, possibilitou que vários/as discentes pudessem se reconhecer e se afirmar como negros/as, ou seja, contribuiu para o processo de construção da identidade negra e de sua expressão estético-política. Possibilitou também que os/as participantes do grupo tivessem o entendimento, a fundamentação teórica e um posicionamento crítico acerca das questões raciais, inclusive, sobre a importância das implementações das Leis Federais 10.639/2003 e 11.645/2008. E nas discussões sobre a construção do Estatuto da Igualdade Racial, instituído pela Lei 12.288/2010.

Interessante destacar que, naquele contexto, foi também implementada a Lei. 11.096/2005, do Programa Universidade para Todos (Prouni), momento em que se percebia a chegada de muitos/as discentes negros/as na Universidade. Um aspecto relevante para o debate das políticas públicas educacionais voltadas para o ensino superior.

Ao analisar os documentos do Geab, constata-se também que o grupo não era formalizado somente em sua constituição, mas também em suas ações, por meio de 
reuniões que antecediam as ações, os encontros periódicos conduzidos, em muitas ocasiões, por um/a professor/a de referência, na estruturação de um calendário semestral, na divulgação das atividades, na articulação com outras frentes militantes na universidade e no diálogo com a comunidade.

Outro resultado expressivo do Geab é que alguns participantes continuaram seus estudos acadêmicos no mestrado, doutorado e pós-doutorado, mantendo o desafio de discutir a questão étnico-racial, bem como outros temas correlatos. A título de exemplo, a base de conhecimento oferecida e construída no Geab contribuiu para que seus participantes expandissem suas militâncias em outros espaços, como na arte, nos movimentos sociais, na universidade. Sobre este último, destaca-se os vários/as participantes que, a partir do acúmulo teórico e intelectual adquirido no grupo, conseguiram aprovação no Programa Internacional de Bolsas de Pós-Graduação da Fundação Ford (Ford Foundation International Fellowships Program - IFP).

Em suma, quando se constitui um grupo de pesquisa e estudo para discutir a educação das relações étnico-raciais, como foi o caso do Geab, é importante considerar e envolver as diversidades raciais, seus significados e sentidos, por isso que esse grupo ficou marcado como um espaço de referência militante, de produção de conhecimento, de apoio e acolhimento de discentes, bem como um lugar coletivo de aprendizado político e reflexivo.

\section{REFERÊNCIAS}

ALMEIDA, Silvio Luiz de. Racismo estrutural. São Paulo: Sueli Carneiro; Pólen, 2019.

BIKO, Steve. Escrevo o que eu quero. São Paulo: Ática, [1978] 1990.

BOSI, Ecléa. O tempo vivo da memória: ensaios de psicologia social. 3. ed. São Paulo: Ateliê Editorial, 2003.

BRASIL. Lei n. 10.639, de 9 de janeiro de 2003. Estabelece as diretrizes e bases da educação nacional, para incluir no currículo oficial da Rede de Ensino a obrigatoriedade da temática "História e Cultura Afro-brasileira", e dá outras providências. Diário Oficial da União, Brasília, 10 jan. 2003. Disponível em: http://www.planalto.gov.br/ccivil 03/leis/2003/l10.639.htm. Acesso em: 2 jan. 2019.

BRASIL. Lei n. 11.096, de 13 de janeiro de 2005. Institui o Programa Universidade para Todos (ProUni), regula a atuação de entidades beneficentes de assistência social no ensino superior; altera a Lei n. 10.891, de 9 de julho de 2004, e dá outras 
providências. Diário Oficial da União, Brasília, DF, 14 jan. 2005. Disponível em: http://www.planalto.gov.br/ccivil_03/_at02004-2006/2005/lei/l11096.htm. Acesso em: 5 jan. 2019.

BRASIL. Lei n. 11.645, de 10 de março de 2008. Altera a Lei n. 9.394, de 20 de dezembro de 1996, modificada pela Lei n. 10.639, de 9 de janeiro de 2003, que estabelece as diretrizes e bases da educação nacional, para incluir no currículo oficial da rede de ensino a obrigatoriedade da temática "História e Cultura Afro-brasileira e Indígena”. Diário Oficial da União, Brasília, 10 mar. 2008. Disponível em: http://www.planalto.gov.br/ccivil_03/ ato2007-2010/2008/lei/l11645.htm. Acesso em: 5 jan. 2019.

BRASIL. Lei n. 12.288, de 20 de julho de 2010. Institui o Estatuto da Igualdade Racial. Diário Oficial da União, Brasília, 21 jul. 2010. Disponível em: http://www.planalto.gov.br/ccivil_03/ato2007-2010/2010/lei/l12288.htm. Acesso em: 15 jan. 2019.

BRASIL. Lei n. 12.711, de 29 de agosto de 2012. Dispõe sobre o ingresso nas universidades federais e nas instituições federais de ensino técnico de nível médio e dispõe sobre outras providências. Diário Oficial da União, Brasília, 29 ago. 2012. Disponível em: http://www.planalto.gov.br/ccivil 03/ ato2011-2014/2012/lei/l12711.htm. Acesso em: 16 mar. 2021.

CHIZZOTTI, Antonio. Pesquisa em ciências humanas e sociais. 11. ed. São Paulo: Cortez, 2010.

GOMES, Joaquim Benedito Barbosa. A recepção do instituto da ação afirmativa pelo Direito Constitucional brasileiro. Revista de Informação Legislativa, a. 38, v. 151, p. 129-152, 2001b. Disponível em: https://www2.senado.leg.br/bdsf/bitstream/handle/id/705/r151o8.pdf?sequence $=4$ \&isAllowed $=\mathrm{y}$. Acesso em: 4 jun. 2019.

GOMES, Joaquim Benedito Barbosa. Ação afirmativa \& princípio constitucional da igualdade. A experiência dos EUA. Rio de Janeiro: Renovar, 2001a.

GOMES, Nilma Lino. Ações afirmativas na UFMG: uma proposta política e pedagógica voltada para alunos e alunas negros. Revista Trabalho \& Educação, Belo Horizonte, v. 12, n.1, p. 73-84, 2003. Disponível em:

https://periodicos.ufmg.br/index.php/trabedu/article/view/8975. Acesso em: 10 jun. 2019.

GOMES, Nilma Lino. Alguns termos e conceitos presentes no debate sobre relações raciais no Brasil: uma breve discussão. In: BRASIL. Educação anti-racista: caminhos abertos pela Lei federal n. 10.639/2003. Brasília, MEC, Secretaria de Educação Continuada e Alfabetização e Diversidade, 2005, p. 39-62.

GOMES, Nilma Lino. Por uma indignação antirracista e diaspórica: negritude e afrobrasilidade em tempos de incertezas. Revista ABPN, v. 10, p. 111-124. 2018. Disponível em: https://doi.org/10.31418/2177-2770.2018.v10.n.26.p111-124. Acesso em: 6 jun. 2019. 
GUIMARÃES, Antonio Sérgio Alfredo. Classes, raças e democracia. 2. ed. São Paulo: Editora 34, 2012.

IANNI, Octavio. Raças e classes sociais no Brasil. São Paulo: Brasiliense, 2004.

IVENICKI, Ana. Diversidade e controle: dilemas da avaliação e do currículo? Ensaio: aval. pol. públ. Educ., Rio de Janeiro, v.26, n. 99, p. 249-256, abr./jun. 2018.

Disponível em: https://doi.org/10.1590/S0104-40362018002609901. Acesso em: 25 maio 2019.

MARÇAL, José Antonio. A formação de intelectuais negros(as): políticas de ação afirmativa nas universidades brasileiras. Belo Horizonte: Nandyala, 2012.

MEMMI, Albert. Retrato do colonizado precedido de retrato do

colonizador. Prefácio de Jean Paul Sartre. Rio de Janeiro: Civilização Brasileira, [1957] 2007.

MIRANDA, Sheila Ferreira. Políticas de identidade no contexto da discussão racial: a academia negra no Brasil. Psicologia \& Sociedade, 29, e171201. 2017. Disponível em: http://dx.doi.org/10.1590/1807-0310/2017v29171201. Acesso em: 4 jun. 2019.

MUNANGA, Kabengele. A difícil tarefa de definir quem é negro no Brasil. Estudos Avançados, v. 18, n. 50. São Paulo, jan./abr. 2004, p. 51-56. Disponível em: http://dx.doi.org/10.1590/So103-40142004000100005. Acesso em: 22 nov. 2018.

MUNANGA, Kabengele; GOMES, Nilma Lino. O negro no Brasil de hoje. São Paulo: Global, 2006.

MUNANGA, Kabengele. Negritude: usos e sentidos. Belo Horizonte: Autêntica, 2009.

MUNANGA, Kabengele. Por que ensinar a história da África e do Negro no Brasil de Hoje? Revista do Instituto de Estudos Brasileiros, v. 1, p. 20-31, 2015.

Disponível em: http://dx.doi.org/10.11606/issn.2316-901X.voi62p20-31. Acesso em: 28 maio 2019.

PÉTRÉ-GRENOUILLEAU, Olivier. A história da escravidão. São Paulo: Boitempo, 2009.

POSADA, Jorge Enrique Mendonza. Vem mulher, vem sempre... Belo Horizonte: Mazza, 1993.

RACIONAIS Mc's. Sobrevivendo no inferno. São Paulo: Companhia das Letras, 2018.

RIBEIRO, Djamila. Lugar de fala. São Paulo: Sueli Carneiro; Pólen, 2019.

SENKEVICS, Adriano Souza. Contra o silêncio racial nos dados universitários: desafios e propostas acerca da Lei de Cotas. Educ. Pesqui., São Paulo, v. 44, e182839. 2018. Disponível em: DOI: http://dx.doi.org/10.1590/S16784634201844182839. Acesso em: 29 maio 2019. 
SILVA, Roberto da.; TOBIAS, Juliano da Silva. A educação para as relações étnicoraciais e os estudos sobre racismo no Brasil. Revista do Instituto de Estudos Brasileiros, Brasil, n. 65, p. 177-199, dez. 2016. Disponível em: DOI: http://dx.doi.org/10.11606/issn.2316-901X.voi65p177-199. Acesso em 27 mai. 2019. ZIEGLER, Jean. Ódio ao ocidente. São Paulo: Cortez, 2011.

\section{SOBRE O AUTOR:}

Daniel Péricles Arruda: é docente da Universidade Federal de São Paulo (UNIFESP), campus Baixada Santista, vinculado ao curso de graduação em Serviço Social e ao Departamento de Saúde, Educação e Sociedade e é coordenador do Grupo de Estudos e Pesquisas sobre Vivências Artísticas, Culturais e Periféricas. É graduado em Serviço Social pela PUC Minas, mestre (bolsista do Ford Foundation International Fellowships Program, turma 2010) e doutor em Serviço Social pela PUC-SP, pósdoutor em Psicologia Social pela PUC-SP, em formação em psicanálise pelo Instituto Langage, e aluno do $2^{\mathrm{O}}$ ano do curso de aprimoramento Clínica Psicanalítica: Conflito e Sintoma, do Instituto Sedes Sapientiae. É arte-educador, rapper e poeta conhecido como Vulgo Elem

\section{Tramitação:}

Recebido em:26/12/2020

Aprovado em:31/o3/2021 